\author{
Pathophysiology \\ Haemostasis \\ and Thrombosis
}

\title{
Assessment of the Risk and the Prophylaxis of Venous Thromboembolism in Surgical Patients
}

\author{
David Bergqvist
}

Department of Surgical Sciences, Section of Surgery, University of Uppsala, Sweden

\section{Key Words \\ Thrombosis · Prevention · Surgery · Low-molecular weight heparin $\cdot$ Fondaparinoux $\cdot$ Ximelagatran}

\begin{abstract}
This review article first deals with risk factors for developing postoperative venous thromboembolism. The various pharmacological prophylactic methods available today are summarized with focus on dominating method low molecular weight heparin and the two new ones, the Xa inhibitor fondaparinux and the Ila inhibitor ximelagatran, both approved in orthopaedic surgery. The optimal timing to start prophylaxis is between 2 hours before and 10 hours after surgery. Evidence is accumulating that some in risk groups prolonged prophylaxis is indicated, ie. elective hip surgery, probably hip fracture surgery and probably also patients operated on for abdominal/pelvic cancer.
\end{abstract}

Copyright @ 2004 S. Karger AG, Basel

\section{KARGER}

Fax +4161306 1234

E-Mail: karger@karger.ch

www.karger.com
In patients undergoing surgery often two or three of the pathophysiological cornerstones of Virchow's triad are altered in a thrombogenic direction: venous stasis during anaesthesia and immobilization, changes in the haemostatic system with activation of the platelet function and coagulation simultaneously with a decreased fibrinolytic activity and at least during some procedures such as orthopaedic surgery of the hip and knee or extensive pelvic dissection endothelial damage. Several risk factors or risk markers have been reported such as type of surgery, increasing age, surgery for malignant disorders, immobilization, previous venous thromboembolism, hyperestrogenemia, varicose veins, preoperative trauma and various biochemical thrombophilic factors such as insufficiency of antithrombin, protein $\mathrm{C}$ and $\mathrm{S}$, activated protein $\mathrm{C}$ resistance (factor V Leiden mutation). One important task is to select the risk patients who are in need of prophylaxis to prevent postoperative venous thromboembolism (VTE). There are some models based on consensus meetings or analyses of existing evidence. They come to basically very similar recommendations. Table 1 summarizes and synthetises risk group classification with estimated thromboembolic complications without prophylaxis on which to base conclusions and recommendations on use of prophylaxis. In Table 2 is seen the most important risk factors. To optimise prophylaxis it seems of value to have simple written recommendations on what to use and when to use it.

David Bergqvist, MD, PhD, FRCS

Department of Surgical Sciences, Section of Surgery,

University of Uppsala,

75185 Uppsala, Sweden

Tel: +46 1861146 33; Fax: +46 1861146 32;

E-mail: david.bergqvist@surgsci.uu.se 
Table 1. Levels of risk for postoperative venous thromboembolism in patients without prophylaxis [33].

\begin{tabular}{|c|c|c|c|c|c|}
\hline Level of risk / Examples & Calf DVT, \% & Prox. DVT, \% & Clinical PE, \% & Fatal PE, \% & Successful prevention strategies \\
\hline $\begin{array}{l}\text { Low risk } \\
\text { Minor surgery in patienst }<40 \text { yr with no } \\
\text { additional risk factors }\end{array}$ & 2 & 0.4 & 0.2 & $<0.01$ & $\begin{array}{l}\text { No specific prophylaxis } \\
\text { Early and "aggressive" mobilization }\end{array}$ \\
\hline $\begin{array}{l}\text { Moderate risk } \\
\text { Minor surgery in patients with additional } \\
\text { risk factors } \\
\text { Surgery in patients aged 40-60 yr with no } \\
\text { additional risk factors }\end{array}$ & $10-20$ & $2-4$ & $1-2$ & $0.1-0.4$ & $\begin{array}{l}\text { LDUH q12h, LMWH ( }<3.400 \text { U daily), } \\
\text { GCS or IPC }\end{array}$ \\
\hline $\begin{array}{l}\text { High risk } \\
\text { Surgery in patients > } 60 \text { yr, or age } 40-60 \text { with additional } \\
\text { risk factors (prior VTE, cancer, molecular hypercoagu- } \\
\text { lability) }\end{array}$ & $20-40$ & $4-8$ & $2-4$ & $0.4-1.0$ & $\begin{array}{l}\text { LDUH q8h, LMWH (>3.400 U daily) or } \\
\text { IPC }\end{array}$ \\
\hline $\begin{array}{l}\text { Highest risk } \\
\text { Surgery in patients with multiple risk factors (age }>40 \text {, } \\
\text { cancer, prior VTE); } \\
\text { Hip or knee arthroplasty, hip fracture surgery } \\
\text { Major trauma, spinal cord injury }\end{array}$ & $40-80$ & $10-20$ & $4-10$ & $0.2-5$ & $\begin{array}{l}\text { LMWH ( }>3.400 \text { U daily), fondaparinux, } \\
\text { oral vitamin K antagonists (INR 2-3) or } \\
\text { IPC/GCS + LDUH/LMWH }\end{array}$ \\
\hline
\end{tabular}

Table 2. Most important risk factors for development of postoperative deep vein thrombosis.

\section{age}

immobilization

trauma

malignancy

varicose veins

estrogen treatment

thrombophilia

Table 3. Thromboprophylactic pharmacological substances with a documented effect and approval.

oral vitamin $\mathrm{K}$ antagonists

dextran

heparin

low molecular weight heparins

fondaparinux

ximelagatran/melagatran

\section{What to Use?}

In Table 3 is shown the thromboprophylactic substances, which are available today and where there is clear documented evidence of an effect. The dominating method today is to use one of the several commercially available low molecular weight heparins. They differ in how they are fragmented from unfractionated heparin (Table 4). Those differences lead to differences in mean molecular weight, the relative inhibition of activated factor II and activated factor X as well as to some differences in various biological test systems. However, there is no strong indications that those differences lead to different clinical effects concerning thromboprophylaxis. At least, to show such potential differences would require randomised studies of quite considerable sample sizes and the question is if this is of practical inter-

Venous Thromboembolism in Surgical Patients est. There are several metanalyses and systematic reviews showing that unfractionated low dose heparin is superior to no prophylaxis both preventing deep vein thrombosis (DVT) and fatal pulmonary embolism as well as total perioperative death $[1,2]$ as well as showing that low molecular weight heparins are not inferior to unfractionated heparin in these respects [3-10]. There are some indications that low molecular weight heparins are in fact better $[5,6]$, but anyhow they are at least more practical as administration once daily is enough. The effect is clear both in general and orthopaedic surgery although the relative effect is less in orthopaedic surgery. In a recent Cochrane analysis comparing either unfractionated heparin or low molecular weight heparin to placebo or no treatment in patients undergoing colorectal surgery, the heparins were significantly better than no treatment in preventing VTE (OR 0.32, 95\% CI 0.20-0.53). [11]. Direct comparison between unfractionated heparin and low molecular weight heparins showed them to be equally effective (OR1.01, 95\% CI 0.67-1.52).

Dextran is equal to low dose heparin concerning prevention of fatal pulmonary embolism but not as effective when it comes to DVT [12]. This effect could, however, be of importance when it comes to the choice of a substance to be used in day care surgery or surgery with extremely short hospitalisation duration.

In recent years two new pharmacological principles have been extensively evaluated in orthopaedic surgery. They are also of theoretical interest as they show that it is possible to reach to a good prophylactic effect by inhibiting certain single factors within the coagulation system - activated factor $\mathrm{X}$ and activated thrombin.

In 1979-80 Lindahl et al [13, 14] discovered the antithrombin binding site of the heparin molecule to be a

Pathophysiol Haemost Thromb 2003/2004;33:358-361 


\begin{tabular}{llll}
\hline Preparation & Method of Preparation & $\begin{array}{l}\text { Mean } \\
\text { Molecular } \\
\text { Weight }\end{array}$ & anti Xa/anti IIa \\
\hline Ardeparin (Normiflo) & Peroxidative depolymerization & 6,000 & 2 \\
Dalteparin (Fragmin) & Nitrous acid depolymerization & 6,000 & $1,9-3,6$ \\
Enoxaparin (Lovenox) & Benzylation and alkaline depolymerization & 4,200 & $3,3-5,3$ \\
Nadroparin (Fraxiparine) & Nitrous acid depolymerization & 4,500 & $2,5-4,0$ \\
Reviparin (Clivarine) & Nitrous acid depolymerization & 4,000 & $>3$ \\
Tinzaparin (Innohep) & Heparinase digestion & 4,500 & $1,5-2,5$ \\
\hline
\end{tabular}

Table 4. Comparison of LMWH preparations.

well defined pentasacharide, which then was synthesized by Choay et al [15], now being clinically available as fondaparinux. In an extensive study programme it has been shown to be significantly better than low molecular weight heparin to prevent venographically postoperative DVT after elective hip and knee surgery and hip fracture surgery [16]. A similar beneficial effect has also been found in patients undergoing abdominal surgery (Agnelli, Bergqvist, Cohen, Geerts PEGASUS unpublished data).

Several studies have shown the thrombin inhibitor recombinant hirudin to be prophylactically effective but for various reasons this has not lead to a wide-spread clinical use. However, there has been intensive research to synthesize thrombin inhibitors, also with an effect after oral administration. Leader in this field has been the oral prodrug ximelagatran, which is metabolised to the active compound melagatran, which also can be used parenterally [17, 18]. Also this substance has been extensively evaluated in orthopaedic surgery, with an effect equal to or better than low molecular weight heparins [19, 20]. Interestingly enough it is absorbed after oral administration already on the third postoperative day after major abdominal surgery [21]. Therefore, prophylactic studies on this group of patients are eagerly awaited.

\section{When to Start?}

Of all the prophylactic studies performed the vast majority have studied preoperative start, in most of them the first dose being given a couple of hours before the operation. After a randomised study it was shown that starting prophylaxis in the evening before surgery was effective [22], quite a few investigators used preoperative start the day before surgery. On the other hand, especially in the USA there has been a clear tendency to start postoperatively (18-24 h), primarily because of the fear of bleeding complications. All options seem to effective and the question is when the optimal time for the first injection is. There is only one randomised study in elective hip surgery, the conclusion being that at least preoperative and postoperative start with dalteparin was equally effective and both significantly better than warfarin which was given in a third arm of the study [23]. This observation lead the authors to perform an analy-

sis of the problem from all published studies, where the starting time was given [24]. From this analysis it was concluded that the optimal interval to start prophylaxis, both from a benefit and a risk perspective, was between around 2 hours preoperatively and 10 hours postoperatively.

\section{When to Stop?}

In the majority of prophylactic trials the duration of prophylaxis has been around one week. However, it has been known since long that fatal pulmonary embolism may occur up to at least 4-6 weeks postoperatively [25] and the question has been raised if this is due to immediate postoperative DVT or if some patients do develop DVT later with a risk for a later embolism. In 1988 Scurr et al [26] published a study supporting the latter assumption. In abdominally operated patients with a negative phlebography at discharge around 25\% developed DVT after discharge (fibrinogen uptake test and plethysmography used for diagnosis). Knowing that patients undergoing elective hip surgery have a prolonged coagulation activation and a decreased venous emptying for a few weeks and also have isolated proximal DVT, where the femoral vein endothelium is locally damaged, we suggested performing a study on prolonged or extended prophylaxis [27]. In fact, we were able to show prolonged prophylaxis (around one month) to be significantly better than standard prophylaxis for around one week to prevent venographic DVT as well as clinical VTE [28]. This was verified in several studies which have been reviewed in two metaanalyses [29, 30] it was clearly shown that the effect was not only on venographic endpoint but also on clinical venous thromboembolism. One study has been performed in hip fracture surgery, showing a highly significant benefit when fondaparinux was used for one month compared to one week [31]. In a study of similar design it was shown that prolonged prophylaxis was also significantly better than in hospital prohylaxis in patients undergoing abdominal/pelvic surgery for malignant disorders [32]. More studies are needed on prolonged prophylaxis in non-orthopaedic surgery but preliminary data seem to verify the observation. 


\section{Conclusion}

It is today possible to define risk factors for the development of postoperative VTE, thereby giving the possibility to recommend prophylactic measures aiming to prevent these complications, fatal pulmonary embolism inclusive. th modern prophylactic methods it is possible to reach the prophylactic effect with a reasonable risk in form of bleeding complications. Those are, however, rare and in many stud- ies not more prevalent than in placebo groups. Data are accumulating indicating that postoperative start of prophylaxis seems a reasonable option if done within 10 hours postoperatively. Prolongation of prophylaxis should be seriously considered in patients undergoing hip surgery and may also be used after abdominal/pelvic cancer surgery. For prolonged prophylaxis an oral substance would be an advantage.

\section{References}

1 Collins R, Scrimgeour A, Yusuf S, Peto R. Reduction in fatal pulmonary embolism and venous thrombosis by perioperative administration of subcutaneous heparin. Overview of results of randomized trials in general, orthopedic, and urologic surgery. N Engl J Med 1988;318:11621173.

2 Clagett GP, Reisch JS. Prevention of venous thromboembolism in general surgical patients. Results of meta-analysis. Ann Surg 1988;208: 227-240.

3 Breddin HK. Low molecular weight heparins in the prevention of deep-vein thrombosis in general surgery. Semin Thromb Hemost 1999;25(Suppl 3):83-89.

4 Clagett G, Anderson F, Geerts W, et al. Prevention of venous thromboembolism. Chest 1998;114: 531S-560S.

5 Jorgensen LN, Wille-Jorgensen P, Hauch O. Prophylaxis of postoperative thromboembolism with low molecular weight heparins. Br J Surg 1993;80:689-704.

6 Koch A, Bouges S, Ziegler S, Dinkel H, Daures JP, Victor N. Low molecular weight heparin and unfractionated heparin in thrombosis prophylaxis after major surgical intervention: update of previous meta- analyses. Br J Surg 1997;84: 750-759.

7 Leizorovicz A, Haugh MC, Chapuis FR, Samama MM, Boissel JP: Low molecular weight heparin in prevention of perioperative thrombosis. BMJ 1992;305:913-920.

8 Mismetti P, Laporte S, Darmon JY, Buchmuller A, Decousus H. Meta-analysis of low molecular weight heparin in the prevention of venous thromboembolism in general surgery. Br J Surg 2001; 88:913-930

9 Nurmohamed MT, Rosendaal FR, Buller HR, et al. Low-molecular-weight heparin versus standard heparin in general and orthopaedic surgery: a meta-analysis. Lancet 1992;340:152-156.

10 Palmer AJ, Schramm W, Kirchhof B, Bergemann R. Low molecular weight heparin and unfractionated heparin for prevention of thrombo-embolism in general surgery: a meta-analysis of randomised clinical trials. Haemostasis 1997;27:65-74.

11 Wille-Jorgensen P, Rasmussen MS, Andersen BR, Borly L. Heparins and mechanical methods for thromboprophylaxis in colorectal surgery. Cochrane Database Syst Rev 2003(4): CD001217.

12 Bergqvist D. Dextran. In: Verstraete M, Fuster V, Topol EJ, eds. Cardiovascular thrombosis. Philadelphia: Lippincott-Raven, 1998:235-250.

Venous Thromboembolism in Surgical Patients
13 Lindahl U, Bäckström G, Thunberg L, Leider I Evidence from a 3-0-suphated D-glucosamine residence in the antithrombin binding sequence of heparin. Proc Natl Acad Sci USA 1980;77:66516655.

14 Lindahl U, Backstrom G, Hook M, Thunberg L, Fransson LA, Linker A. Structure of the antithrombin-binding site in heparin. Proc Natl Acad Sci USA 1979;76:3198-3202.

15 Petitou M, Duchaussoy P, Lederman I, et al. Synthesis of heparin fragments. A chemical synthesis of the pentasaccharide O-(2-deoxy-2-sulfamido-6-O-sulfo-alpha-D-glucopyranosyl)-(1-4) -O-(beta-D-glucopyranosyluronic acid)-(1-4)-O(2-deoxy-2-sulfamido-3,6-di-O-sulfo-alpha-D-glu copyranosyl)-(1-4)-O-(2-O-sulfo-alpha-L-idopyranosyluronic acid)-(1-4)-2-deoxy-2-sulfamido-6O-sulfo-D-glucopyranose decasodium salt, a heparin fragment having high affinity for antithrombin III. Carbohydr Res 1986;147:221236.

16 Turpie AG, Bauer KA, Eriksson BI, Lassen MR Fondaparinux vs enoxaparin for the prevention of venous thromboembolism in major orthopedic surgery: a meta-analysis of 4 randomized doubleblind studies. Arch Intern Med 2002;162:18331840 .

17 Gustafsson D, Antonsson T, Bylund R, et al. Effects of melagatran, a new low-molecularweight thrombin inhibitor, on thrombin and fibrinolytic enzymes. Thromb Haemost 1998;79:110 118.

18 Eriksson UG, Bredberg U, Hoffmann KJ, et al. Absorption, distribution, metabolism, and excretion of ximelagatran, an oral direct thrombin inhibitor, in rats, dogs, and humans. Drug Metab Dispos 2003:31:294-305.

19 Eriksson BI, Dahl OE: Prevention of venous thromboembolism following orthopaedic surgery: clinical potential of direct thrombin inhibitors. Drugs 2004;64:577-595.

20 Evans HC, Perry CM, Faulds D. Ximelagatran/ Melagatran: a review of its use in the prevention of venous thromboembolism in orthopaedic surgery. Drugs 2004;64:649-678.

21 Bergqvist D, Sohlberg J-H, Holmdahl L, et al. Pharmacokinetics, preliminary efficacy and safety of subcutaneous melagatran and oral ximelagatran. A multicentrestudy on on thromboprophylaxis in elective abdominal surgery. Clin Drug Invest 2004;24:127-136.

22 Bergqvist D, Burmark US, Flordal PA, et al. Low molecular weight heparin started before surgery as prophylaxis against deep vein thrombosis: 2500 versus 5000 XaI units in 2070 patients. Br J Surg 1995;82:496-501.
23 Hull RD, Pineo GF, Francis C, et al. Low-molecular-weight heparin prophylaxis using dalteparin extended out- of-hospital vs in-hospital warfarin/out-of-hospital placebo in hip arthroplasty patients: a double-blind, randomized comparison. North American Fragmin Trial Investigators. Arch Intern Med 2000;160:2208-2215.

24 Hull RD, Pineo GF, Stein PD, et al. Timing of initial administration of low-molecular-weight heparin prophylaxis against deep vein thrombosis in patients following elective hip arthroplasty: a systematic review. Arch Intern Med 2001; 161: 1952-1960.

25 Bergqvist D, Lindblad B. A 30-year survey of pulmonary embolism verified at autopsy: an analysis of 1274 surgical patients. Br J Surg 1985;72:105108.

26 Scurr JH, Coleridge-Smith PD, Hasty JH. Deep venous thrombosis: a continuing problem. BMJ 1988;297:28.

27 Bergqvist D. Long-term prophylaxis following orthopedic surgery. Haemostasis 1993;23(Suppl 1):27-31.

28 Bergqvist D, Benoni G, Bjorgell O, et al. Lowmolecular-weight heparin (enoxaparin) as prophylaxis against venous thromboembolism after total hip replacement. N Engl J Med 1996;335:696700.

29 Hull R, Pineo G, Stein P, et al. Extended out-ofhospital administration of low molecular weight heparins or placebo in the prophylaxis of acute venous thrombosis: a systematic review. Ann Intern Med 2001;135:858-869.

30 Eikelboom JW, Quinlan DJ, Douketis JD. Extended-duration prophylaxis against venous thromboembolism after total hip or knee replacement: a meta-analysis of the randomised trials. Lancet 2001;358:9-15.

31 Eriksson BI, Lassen MR: Duration of prophylaxis against venous thromboembolism with fondaparinux after hip fracture surgery: a multicenter, randomized, placebo-controlled, double-blind study. Arch Intern Med 2003;163:1337-1342.

32 Bergqvist D, Agnelli G, Cohen A, et al. Duration of prophylaxis against venous thromboembolism with enoxaparin after surgery for cancer. N Engl J Med 2002;346.

33 Geerts WH, Pineo GF, Heit JA, Begqvist D, Lassen MR, Colwall CW, Ray JG. Prevention of venous thromboembolism. Chest 2004;236(3 Suppl):3388-4005. 